\title{
Game theoretic approach for flood risk management considering a financial model
}

\author{
Mahsa Moosakhaani ${ }^{1}$, Lida Salimi ${ }^{\dagger}$, Mohammad Taghi Sadatipour ${ }^{1}$, Mohammad Hossein Niksokhan ${ }^{2}$, \\ Mohammad Rabbani ${ }^{1}$ \\ ${ }^{1}$ Department of Environmental Engineering, Faculty of Marine Science and Technology, North Tehran Branch, Islamic Azad University, Tehran, Iran \\ ${ }^{2}$ School of Environment, College of Engineering, University of Tehran, Iran
}

\begin{abstract}
In process of flood risk management, there is usually a conflict between the governments, insurance companies and people as players in sharing financial responsibilities, because of how calculate insurance premium, compensation and governmental assistances. In order to this conflict resolution in this paper a new methodology is proposed based on game theoretic approach by using Nash equilibrium method, that for the first time, the payoff functions of insurance companies and government have been associated to each other. In this method, according to maximization of player's payoffs, the best response has been found and for the first time, comprehensive financial model has been developed for sharing players' financial responsibilities in flood risk management plans. In order to increase the accuracy of flood insurance calculations, the parameters of deductible and franchise have been applied. The key findings indicate, success of flood risk management plans depend on purchasing flood insurance with full coverage and government financial assistances simultaneously. The developed flood insurance plan has most sensitivity to parameters of deductible and insurance rate. This model could be utilized as practical and academic model in flood risk management. The applicability and efficiency of the methodology are examined in Northeast of Tehran as capital of Iran.
\end{abstract}

Keywords: Game theory, Insurance, Iran, Nash Equilibrium, Strategy

\section{Introduction}

In recent decades, climate change and global warming have melted snow and destroyed glaciers, and finally rising in sea and ocean levels. Rise in precipitation and temperature in the watershed will have serious effect on water balance components on both spatial and temporal scale and causes losses [1]. Therefore, identification and management of these phenomena to prevent and manage their losses has become more important in recent years. According to statistics, flooding is the most damaging type of natural hazard worldwide [2]. The studies indicate that among all the natural disasters which have been identified, the most frequent refers to flooding and in terms of casualties, this phenomenon is in the first place before drought and storms [3].

In relation to flood hydrological studies, one of the most important factors is access to appropriate data to develop stream gauging network. Based on a proposed model framework using the di- mensionless index flood by Ibeje \& Ekwueme, the scarcity of long and precise flood records would continue to be a grave challenge [4]. The researches show, increasing of collected data accuracy by integration of techniques in particular GIS with remote sensing and Internet of Things (IOT) lead to do more studies that are accurate [5]. In addition, combination of the features (frequency and so on) by probabilistic approach is appeared to be a well-improved method to describe the hydrologic phenomenon [6].

In a research, it has been incorporated and tested the Archimedean and Gaussian copulas in deriving the bivariate distribution analysis of the annual series between flood peak and volume (P-V) and flood peak flow and duration (PD) pairs. Investigation has been revealed that the value of bivariate hydrologic risk statistics incrementally increases over the plan service time, at the same time, it augmentation diminish in the return period of flood volume and duration [7].

These investigations show accurate calculations of flood, lead
This is an Open Access article distributed under the terms of the Creative Commons Attribution Non-Commercial License (http://creativecommons.org/licenses/by-nc/3.0/) which permits unrestricted non-commercial use, distribution, and reproduction in any medium, provided the original work is properly cited.

Copyright (C) 2022 Korean Society of Environmental Engineers
Received August 06, 2021 Accepted December 20, 2021

${ }^{\dagger}$ Corresponding author

E-mail: 1_salimi@iau-tnb.ac.ir

Tel: +98-912-240-14-37 Fax: +98-21-7700-98-48

ORCID: 0000-0003-3967-2464 
to improve decision-making methods in management of this phenomenon. There are several strategies in contributing of flood loss compensation through insurance or financial assistance [8].

Insurance makes an extremely important part in flood financial risk management by risk transferring to insurance companies and capital markets and there will be a decrease in contributions of losses between beneficiaries [9, 10]. The households or people, who voluntarily or mandatorily purchase flood insurance, are more likely to take risk reduction measures than the uninsured people. This is statistically significant for building with water-resistant materials, having a water-resistant floor, and elevating utility and electric installations [11]. In addition, the research shows that the extension and analysis method of Surface Water Flood event model is differ in some elements including the extension, the liability, period of merged insurance claims and approaches which are utilized for model expansion in addition with credibility [12].

The flood insurance additionally is considered in Europe, where every country has created special protection courses of action because of various hazard profiles and public policy inclinations to calculate premiums based on the risk [13].

The property owner's insurance purchasing is affected by the low salience of flood risk and their behavioral functions have a major impact on purchasing insurances decisions [14]. A drawback of risk-based premiums is that they might be excessively expensive for low-salary people in high-risk locations. Therefore, accurate calculation of premium and creating transparency in order to design and provide insurance policies commensurate with household income lead to increase in the people's desire to purchase insurance policy [15], the quantitative incorporation of social data can improve flooding exposure estimates [16].

The research shows usually people are not willing to buy flood insurance with full coverage. On the other side, there is not any comprehensive plan and special mechanism for governmental assistance in flood occurrence as one of the main players in flood risk management plans. Therefore, Flood risk management plans involve conflicts arising from opposing interests of players (households' or property owners, insurance companies and the government). Though these conflicts have existed for many years, nowadays it has been more serious primarily due to increasing rate of flood occurrence and requirement of existence flood insurance.

Therefore, it is necessary to present a comprehensive plan in which all stakeholders or players to share their financial responsibilities in plan of flood risk management. The lack of comprehensive plan in which all players are responsible creates conflict. Therefore the coordination, management and determining of players who are beneficiary for sharing flood losses responsibility is followed by some challenges and it leads to formation strategic condition. In other words, the decisions will not be made in static condition and ultimately it will be effective on own final decision of other players. The players tend to maximize their efficiency called payoff, and it makes conflict.

In order to investigate these challenges, a variety of studies has been carried out. In modelling of this strategic condition with multi players, the game theory usually has been used to find game. The methods of conflict resolution, first developed in the mid-1980s, have been expressed the limit of breaking down the turn of events and inner instruments of a contention. In past decades, many studies have been carried out for developing model in conflict resolution in game theory method [17].

In a research, as an analyzing in the written form, the premium dynamic is modeled and analyzed thorough various game theory methods regarding the average market premium. Furthermore, the insurer equilibrium premium vitals in a rival market have been examined [18]. In other study tried to formulate a rather stylized insurance market with adverse selection as a standard duopoly. The indicated request capacities and benefits demonstrated that a Nash equilibrium method in pure strategies exists if and only if the notable Rothschild - Stiglitz allocation is efficient [19].

In a research in order to present humanitarian relief after the catastrophe, a Generalized Nash Equilibrium network model has been expanded by nongovernmental organizations. In this viewpoint, game was specified systemically as an optimization problem and in Hurricane Katrina has been analyzed [20].

In other paper, the possible increase of the average risk-based flood insurance premium in the period of 2015 to 2055 illustrated when a lack of risk decrease occurred by people who were encountered with flooding [21].

According to the importance of implementation comprehensive model to share financial responsibility between players and their strategies in hazardous regions mainly in developing countries, in this paper, Tehran as the capital of Iran has been studied and Golab Darreh and Darband Rivers have been selected as the flood-prone areas. The considerable and irrecoverable financial losses and casualties in flood occurrence in August 1987 [22] indicates the requirement and importance of flood risk management in this region.

Therefore, in this paper has been tried to develop game theory model based on flood losses for sharing players' financial responsibilities and the role of all players in flood risk management plans have been modeled by game theory approach. For this purpose, payoff functions, action profiles and strategy profiles of all players have been calculated.

In addition, the payoff functions of insurance companies and the government have been associated to each other using parameters of performance tax, obligatory reinsurance premium and obligatory reinsurance loss. Finally, in order to increase the calculations accuracy of insurance premium and flood losses control the parameters of franchise and deductible have been considered in proposed flood insurance plans.

Subsequently, investigating related research about conflict resolution shows, for the first time Nash Equilibrium method has been used in modelling of players' financial responsibilities for flood loss compensation in this paper. The essence of mentioned game in this paper is non-cooperative. In this condition, the players have no motivating force to stray from the cooperative solution, which on that they ought to adjust their payoffs such that total maximum solution becomes identical to a game equilibrium Nash method [23].

Purpose of the selection of this method is developing a comprehensive financial model in which the payoff functions of all players is considered simultaneously and their financial responsibilities are calculated. The Nash theory is well able to calculate these values in non-cooperative game model.

It should be noted that, for calculating flood economic losses in this research, the result of calculations related to work of 
Moosakhaani et al. [22] article, has been used and scenarios of $\mathrm{D}_{0}, \mathrm{D}_{1}, \mathrm{D}_{2}$ and $\mathrm{D}_{3}$ have been designed based on that.

One of the most important challenges in this research is that there is no comprehensive flood insurance plan in study area. Flood risk in Iran is presented as one of the additional cover in fire insurance policies; it does not include any consideration of accurate estimate of flood loss. The calculations are not based on flood risk and in which that does not risk assessment according to case study area condition. Therefore, the flood insurance premium calculation does not have enough accuracy.

To solve this problem in this paper, six flood insurance policies were developed in the form of (A, B, C plans) for public (property owner) and (A', B', $C^{\prime}$ plans) for the government. These insurance plans were calculated with cooperation of Iran insurance company (As the only representative of the public sector in the insurance industry in Iran), Asia insurance company and MA insurance company (As representatives of the private sector in the insurance industry in Iran).

After collection essential data about governmental financial assistance to public in various condition, loss compensation by insurance companies and insurance premium paid by insured over the years of 2013-2018 and calculation of payoff functions for each players considering various parameters, during six different scenarios, the action profiles and strategy profiles of each players have been calculated and assigned.

Ultimately, in game equilibrium, where on that, every players search for maximizing their payoffs, in which the payoffs for all players are maximized, the Nash equilibrium method has been found. A comprehensive financial model for flood risk management in sharing responsibilities of each players by considering their financial obligations has been developed, that is model could be used practically and academically in insurance industry and other researches.

This paper consists of three main sections illustrate the steps of doing this research, which follows:

1) Study Design: Identificating the content of studied system; Assessment of conflict between players.

2) Method of Study: Identification of conflict resolution method.

3) Data Analysis: Calculating payoff function of players/ action profile of players/ calculating strategy profile of players; Conflict resolution.

4) Conflict resolution: Developing comprehensive financial model for flood risk management.

\section{Mathematical Model and Method}

\subsection{Study Area}

The Golab Darreh and Darband Rivers are parts of Tehran-Karaj basin in Iran. These are headwaters from the Tochal Heights in north of Tehran which confluente each other in Maghsoud Beyk channel in northeast area of Tehran as capital of Iran and ultimately they flow into Qom Namak Lake.

The study area in Golab Darreh River from the geographical location is $\mathrm{x}=539,898 \mathrm{~m}$ and $\mathrm{y}=3,965,700 \mathrm{~m}$, length of 2,467 $\mathrm{m}$. The geographical location of Darband River is $\mathrm{x}=538,748 \mathrm{~m}$ and $\mathrm{y}=3,962,625 \mathrm{~m}$ with length of 2,415 $\mathrm{m}$ and Maghsoud Beyk

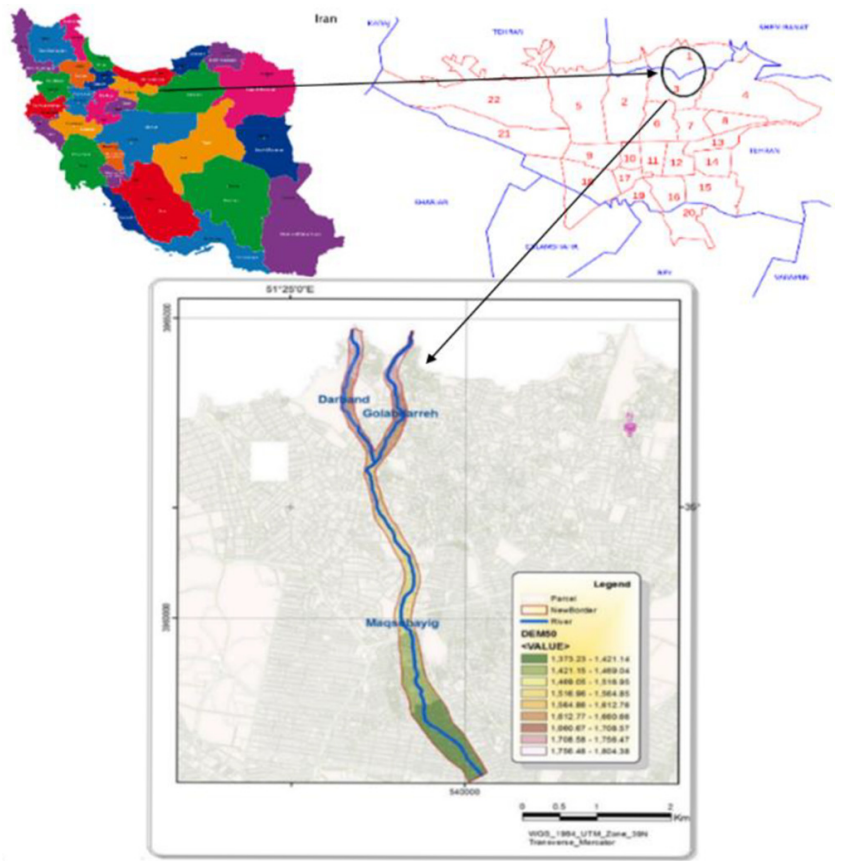

Fig. 1. Location of study area.

Channel's geographical is $\mathrm{x}=540,232 \mathrm{~m}$ and $\mathrm{y}=3,957,386 \mathrm{~m}$ with length of $5,846 \mathrm{~m}$ which is illustrated in Fig. 1. In order to do this research, the meteorological data, physiographical data and hydrological data from 36 years ago have been continued up to statistical year of 2016-2017 have been gained relevant to Darband and Golab Darreh Rivers and Maghsoud Beyk Channel [22].

\subsection{Methods}

\subsubsection{Proposed model framework}

It is necessary mention to focus on three basic sections in this paper: Study design; Method of study; Data analysis.

The main components of the proposed methodology in this research in study design has five steps (Fig. 2):

\subsubsection{Study design}

2.2.2.1. The content of studied system has been identified: As mentioned previously, for flood economic loss in case study area in this paper, the result of calculations related to paper of Moosakhaani et al. [22], has been used and scenarios of $D_{0}, D_{1}$, $\mathrm{D}_{2}$ and $\mathrm{D}_{3}$ have been designed based on that. According to flood economic loss amount and requirement of loss compensation, implementation of flood risk management plans is necessary. Therefore, all stakeholders or players have been identified and their strategies have been developed.

As indicated before, the players are people (property owners), insurance companies and the government.

In flood occurrence, the people who bought the insurance policy will receive compensation in proportion to the sum insured by claiming from the insurance companies. On the other hand, the government also financially assists according to the amount of loss to the damaged people. 


\subsubsection{Creating conflict between players}

Based on what has been mentioned before, there is usually a conflict in flood risk management process because of players' strategies; they tend to maximize their payoff and it causes conflict. These strategies include of government financial assistance (In the format of buying insurance or direct financial assistance), flood loss compensation by insurance companies and purchasing flood insurance by property owner. This situation lead to form strategic condition, which in this paper, has been, used game theory to model it.

\subsubsection{Method of study}

\subsubsection{Identification of conflict resolution method}

In this step, conflict resolution method is identified based on essence of game. Selected method in this section is Nash equilibrium in game theoretic approach. The game theory method manages strategic condition between decision makers as players. Every player has a payoff function that represents his strategy among multiple-choice alternatives and the requirements has been identified with this arrangement of discretionary decisions. In essence, this method is used in a status in which intelligent decisions are inevitably individualistic. A mode where player's payoff relies on her self-function in addition with the operations of other assistants. Every single player search for maximizing his assumed payoff is game equilibrium in concept that named Nash method [25]. In game theory, the Nash equilibrium method, named after the mathematician John Forbes Nash Jr., proposed solution of a non-cooperative game involving at least two players in which every player is expected to know the equilibrium strategies of other players, and no player has anything to gain by changing just their own strategy. A strategy that is the best response, which produces the maximum payoff for a player that is named game equilibrium, taking other players' strategies as given. If every player has selected a strategy and action plan choosing its own action dependent on what it has happen so far in the game. Players are assumed to take rational choices and to optimize their payoff function [24]. Moreover, he is aware that every other player is rational too, In addition sees that every other player is informed about the fact that each player is rational and so on.

In this method, any players can increase its own expected payoff by changing its strategy while different players keep theirs unaltered, at that point the current set of system decisions comprises a Nash equilibrium method and this situation is equilibrium for all players [26]. In game theory, strategy profile is a set of strategies for all players, which fully specifies all actions in a game, and action profile is a list of actions, one for each player. In every game with $\mathrm{n}$ players, there is $2^{n}$ strategy [26]. Action profile is the action that each player takes at each step and strategy profile is the actions that each player takes whole the game according to the decisions of other players. In fact Nash Equilibrium method is strategic game with perfect information an action profile $a^{*} \in \mathrm{A}$ with the feature that there is no possibility for any player to act better by selecting a function which is dissimilar to $a_{i}^{*}$ given that all other players stick to $a_{-i}^{*}$. An action profile for player is opponents by $a_{-i} \in$ $A_{-i}$ is indicated. The action profile $a^{*} \in \mathrm{A}$ in a strategic game is a Nash Equilibrium when for each player i: $u_{i}\left(a^{x}\right) \geq u_{i}\left(a_{i}^{x}, u_{-i}^{x}\right)$ for every action $a_{i}$ of player i. Where $u_{i}(0)$ is a payoff function representing player i's preferences [26].

\subsubsection{Data analysis}

\subsubsection{Forming equations in Nash equilibrium method}

According to player's strategies, the action profiles and strategy profiles has been calculated in this step, in following:

\subsubsection{Property owner (people) payoff function}

Each property owner as player has a set of actions to choose from, $A=\left\{a_{(n, i)}\right\}$ where A is the set of possible actions and $\mathrm{a}$ is the chosen insurance coverage plan $\mathbf{n}$ offered by the associated company i. The payoff function illustrated that in choosing a plan at each repetitive step $t$, some factors will be regarded by every property owner including the each property owner considers his or her current wealth, the indemnity obtained from the insurance company. In selecting a plan at each iterative step t, each property owner considers his or her current wealth, the indemnity received from the insurance company if a natural hazard causes damages to the building, the amount of tax paid, and the compensation paid by the government after a natural disaster event, the payoff function as shown in Eq. (1) [27].

$$
\mathrm{W}_{\mathrm{P}}^{\mathrm{t}+1}=\mathrm{W}_{\mathrm{P}}^{\mathrm{t}}-\mathrm{P}_{\mathrm{n} . \mathrm{i}}-\mathrm{T}-\mathrm{D}+\mathrm{C}_{\mathrm{n} i}+\mathrm{G}
$$

$\mathrm{W}_{\mathrm{P}}^{\mathrm{t}+1}=$ Amount of wealth of property owner $\mathrm{P}$ at time $\mathrm{t}+1$

$\mathrm{W}_{\mathrm{P}}^{\mathrm{t}} \quad=$ Property owner initial amount of wealth at time step $\mathrm{t}$

$\mathrm{P}_{\mathrm{n} . \mathrm{i}} \quad=$ Insurance premium paid by a property owner to insurance company i using plan $\mathrm{n}$

$\mathrm{T}=$ Taxes paid by the property owner

$\mathrm{D} \quad=$ Loss cost due to the flood occurrence

$\mathrm{C}_{n . \mathrm{i}} \quad=$ Compensation paid by the insurance company $\mathrm{i}$ if the property owner is utilizing plan $n$ according to the intensity and loss due to the flood

$\mathrm{G} \quad=$ Compensation paid by the government

\subsubsection{Insurance companies payoff function}

To above-noticed items, three insurance companies are presenting insurance plans, which extend from limited to complete the insurance coverage. In fact, insurance companies present six different types of insurance coverage to the people and the government as insured. In general, insurance coverage plans to the people, including building structures and used building construction materials and furniture. Whereas insurance coverage provided to the government, including only building structures and building construction materials.

A decision for each company is to determine the distribution and pricing of plans to offer the property owner and the government. Relevantly, the illustration of the insurer's payoff function, as shown in Eq. (2) [27].

$$
\mathrm{W}_{\mathrm{i}}^{\mathrm{t}+1}=\mathrm{W}_{\mathrm{i}}^{\mathrm{t}}+\left\{\begin{array}{ll}
\sum_{\mathrm{p}=1}^{\mathrm{p}}\left(\mathrm{P}_{\mathrm{n} \cdot \mathrm{x}}-\mathrm{C}_{\mathrm{n} \cdot \mathrm{x}}\right) & \text { if } \mathrm{x}=\mathrm{i} \\
\sum_{\mathrm{p}=1}^{\mathrm{p}} \mathrm{P}_{\mathrm{n} \cdot \mathrm{x}} & \text { otherwise }
\end{array}\right\}+\mathrm{G}^{\prime}-\mathrm{T}^{\prime}-\mathrm{T}^{\prime \prime}
$$

$\mathrm{T}^{\prime}=$ Performance tax paid to the government

$\mathrm{T}^{\prime \prime}=$ payment to the government for obligatory reinsurance premium (Obligatory reinsurance is a treaty that requires an insurer (insurance company) automatically send all policies on its books that fall within a set list of criteria to a reinsurer. 
Under the terms of an obligatory reinsurance agreement, also called an automatic treaty, the reinsurer is obliged to accept these policies [28].)

As mentioned previous, for the first time in this study, the payoff functions of insurance companies and the government have been associated to each other using performance tax, obligatory reinsurance premium and obligatory reinsurance loss parameters.

\subsubsection{The government payoff function}

One of the most important factors to analyze the financial compensation for damaged residential area, due to a flood occurrence, is the government action. This can be achieved in several ways. In this paper for the first time, the government action is considered by financial assistance to people in reconstructing (In the format of buying insurance or direct financial assistance) simultaneously.

Finally the government's payoff function, as shown in Eq. (3) [27].

$$
\mathrm{W}_{\mathrm{G}}^{\mathrm{t}+1}=\mathrm{W}_{\mathrm{G}}^{\mathrm{t}}+\sum_{\mathrm{P}=1}^{\mathrm{P}}\left(\mathrm{T}_{\mathrm{P}}-\mathrm{G}_{\mathrm{P}}\right)-\mathrm{D}-\mathrm{G}^{\prime}+\mathrm{T}^{\prime}+\mathrm{T}^{\prime \prime}
$$

$\mathrm{G}^{\prime}=$ payment to the insurance company for obligatory reinsurance loss

\subsubsection{Player's action profile}

As previously explained, three insurance companies presented insurance plans based on own economic condition and risk level of case study so that, based on these, the insurance companies' action profile have been obtained (Table 1).

In accurate calculation of insurance premium, there are several factors. Deductible as one important factor is usually expressed as percentages of loss, is a part of expenses that must be paid out of pocket by an insured before an insurer will pay any expenses [29]. This parameter is used for limitation of insurer responsibility, sharing insured in loss payment, and it is one of the most important factors in risk calculation. The existence of a deductible in insurance policy, if not always, but in many cases, causes the insured to pay more attention to precautions and it is in the interest of society [30]. Franchise is another parameter defined in insurance policy that is the minimum threshold of the insurance companies' financial

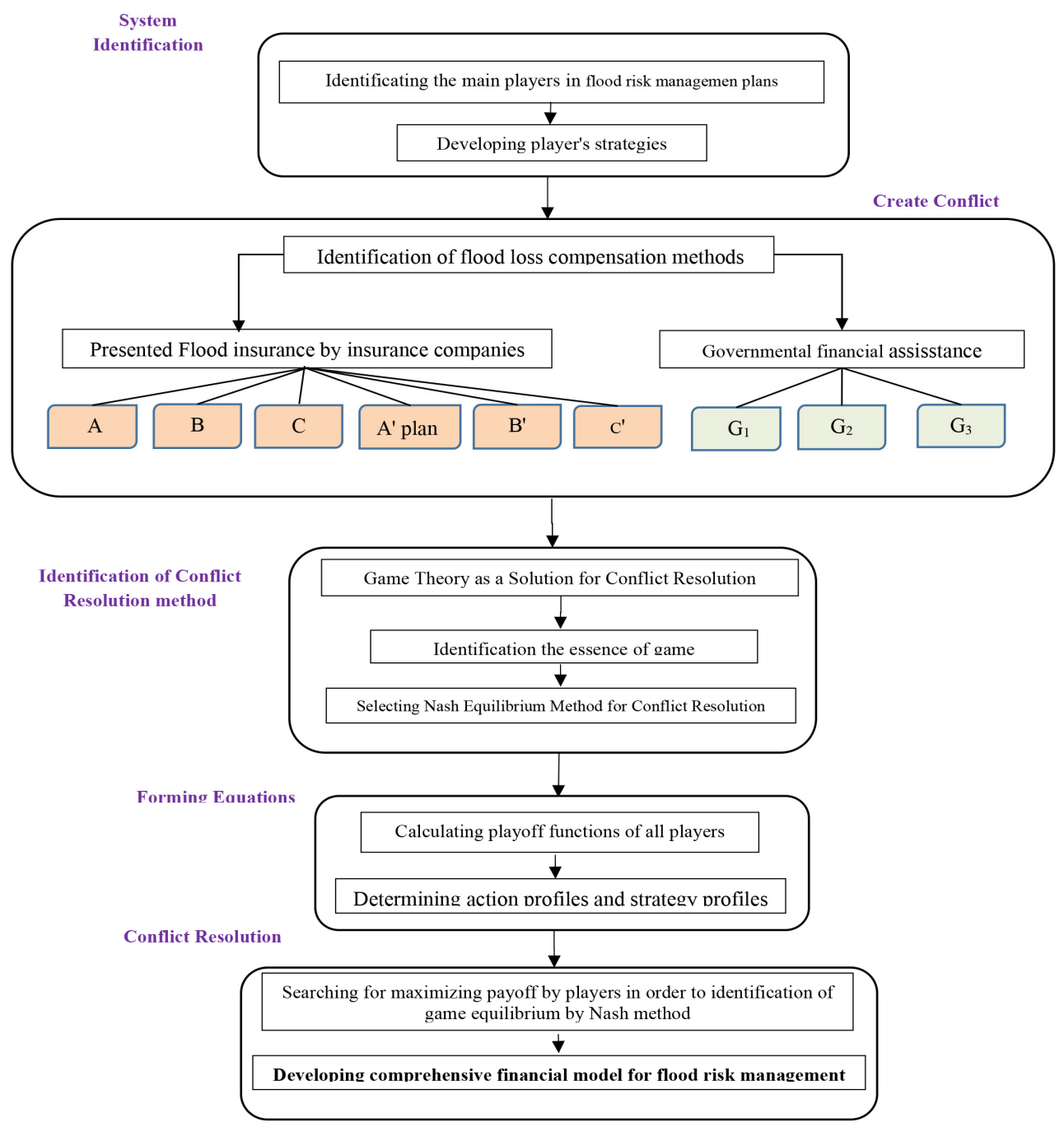

Fig. 2. Flowchart of proposed methodology for conflict resolution. 
obligation. In addition, this parameter helps to reduce the administrative costs of insurance companies as well as non-payment of fraudulent losses [31]. Unfortunately, there is not considerable attention to these parameters, despite the important of them. In this paper, in order to increase the accuracy of calculations insurance premium, the franchise is defined as a fixed number of each or every loss mentioned in Table 1.

The government financial assistance $\left(\mathrm{G}_{0}, \mathrm{G}_{1}, \mathrm{G}_{2}\right.$, and $\left.\mathrm{G}_{3}\right)$ based on the flood economic loss have been calculated in paper of Moosakhaani et al. [22] and scenarios $\left(D_{0}, D_{1}, D_{2}\right.$ and $D_{3}$ ) have been defined. Therefore, the government's action profiles are in Table 2.

The action profiles of property owners are in Table 3 .

2.2.4.6. Player's strategy profile

Due to the previous mentioned, these players are those who decide independently on conflict of flood risk management and have separate powers. Given that the number of players is 5, including the people, the government, Iran insurance company, Asia insurance company and MA insurance company, there will be $2^{5}=32$ strategy profiles. In addition based on action profile on Table 1, 2, 3, the player's strategy profile has been calculated in supplementary material (Table S1).

\subsubsection{Conflict resolution}

Finally, according to flood loss amount in scenarios of $\mathrm{D}_{0}, \mathrm{D}_{1}$, $\mathrm{D}_{2}$ and $\mathrm{D}_{3}$ by using Nash equilibrium method and searching for maximizing payoff for all players, comprehensive financial model for flood risk management has been developed. It should be noted that in this step, the sensitivity analysis of developed model in related to each of the parameters is reviewed and the related results has been presented in the results section.

Table 1. Insurance Companies' Action Profile

\begin{tabular}{|c|c|c|c|c|c|}
\hline $\begin{array}{l}\text { Insurance } \\
\text { plan }\end{array}$ & $\begin{array}{c}\text { Name of } \\
\text { Insurance company }\end{array}$ & $\begin{array}{c}\text { Insurance rate } \\
(/ \mathbf{1}, \mathbf{0 0 0})\end{array}$ & $\begin{array}{l}\text { Franchise } \\
\text { (USD) }\end{array}$ & $\begin{array}{l}\text { Deductible } \\
\text { (USD) }\end{array}$ & Insurance coverage \\
\hline \multicolumn{6}{|c|}{$\begin{array}{c}\text { In flood occurrence with loss }\left(\mathrm{D}_{0}=122,202 \text { USD), the insurance companies do not have action, because flood loss amounts is }\right. \\
\text { less than franchise. }\end{array}$} \\
\hline A & Iran & 0.31 & 150,000 USD in each or every loss & $\begin{array}{c}10 \% \\
\text { sum insured }\end{array}$ & $\begin{array}{l}\text { 1. Building structures } \\
\text { 2. Building construction materials } \\
\text { 3. Furniture }\end{array}$ \\
\hline B & Asia & 0.35 & 150,000 USD in each or every loss & $\begin{array}{c}15 \% \\
\text { sum insured }\end{array}$ & $\begin{array}{l}\text { 1. Building structures } \\
\text { 2. Building construction materials } \\
\text { 3. Furniture }\end{array}$ \\
\hline $\mathbf{C}$ & MA & 0.25 & 150,000 USD in each or every loss & $\begin{array}{c}20 \% \\
\text { sum insured }\end{array}$ & $\begin{array}{l}\text { 1. Building structures } \\
\text { 2. Building construction materials } \\
\text { 3. Furniture }\end{array}$ \\
\hline $\mathbf{A}^{\prime}$ & Iran & 0.31 & 150,000 USD in each or every loss & $\begin{array}{l}10 \% \\
\text { sum insured }\end{array}$ & $\begin{array}{l}\text { 1. Building structures } \\
\text { 2. Building construction materials }\end{array}$ \\
\hline $\mathbf{B}^{\prime}$ & Asia & 0.35 & 150,000 USD in each or every loss & $\begin{array}{l}15 \% \\
\text { sum insured }\end{array}$ & $\begin{array}{l}\text { 1. Building structures } \\
\text { 2. Building construction materials }\end{array}$ \\
\hline $\mathbf{C}^{\prime}$ & MA & 0.25 & 150,000 USD in each or every loss & $\begin{array}{c}20 \% \\
\text { sum insured }\end{array}$ & $\begin{array}{l}\text { 1. Building structures } \\
\text { 2. Building construction materials }\end{array}$ \\
\hline
\end{tabular}

Table 2. The Government's Action Profile

\begin{tabular}{|c|c|}
\hline Flood loss & Action \\
\hline $\mathrm{D}_{0}$ & $\begin{array}{l}\text { The government does not have action, because in flood occurrence with loss amount of } D_{0}=122,202 \text { USD, people can } \\
\text { return to before flood occurrence conditions. }\end{array}$ \\
\hline $\mathrm{D}_{1}$ & $\begin{array}{l}\text { Provides assistances for the people by: } \\
\text { 1. Compensation through purchased } A^{\prime} \text { Insurance plan from Iran insurance company }+G_{1} \text { amount in cash } \\
\text { 2. Compensation through purchased } B^{\prime} \text { Insurance plan from Asia insurance company }+G_{1} \text { amount in cash } \\
\text { 3. Compensation through purchased } C^{\prime} \text { Insurance plan from MA insurance company }+G_{1} \text { amount in cash } \\
\text { 4. Only by } G_{1} \text { amount in cash. }\end{array}$ \\
\hline $\mathrm{D}_{2}$ & $\begin{array}{l}\text { Provides assistances for the people by: } \\
\text { 1. Compensation through purchased } A^{\prime} \text { Insurance plan from Iran insurance company }+G_{2} \text { amount in cash } \\
\text { 2. Compensation through purchased } B^{\prime} \text { Insurance plan from Asia insurance company }+G_{2} \text { amount in cash } \\
\text { 3. Compensation through purchased } C^{\prime} \text { Insurance plan from MA insurance company }+G_{2} \text { amount in cash } \\
\text { 4. Only by } G_{2} \text { amount in cash. }\end{array}$ \\
\hline $\mathrm{D}_{3}$ & $\begin{array}{l}\text { Provides assistances for the people by : } \\
\text { 1. Compensation through purchased } A^{\prime} \text { Insurance plan from Iran insurance company }+G_{3} \text { amount in cash } \\
\text { 2. Compensation through purchased } B^{\prime} \text { Insurance plan from Asia insurance company }+G_{3} \text { amount in cash } \\
\text { 3. Compensation through purchased } C^{\prime} \text { Insurance plan from MA insurance company }+G_{3} \text { amount in cash } \\
\text { 4. Only by } G_{3} \text { amount in cash. }\end{array}$ \\
\hline
\end{tabular}


Table 3. The Property Owner's Action Profile

\begin{tabular}{l} 
Flood loss \\
\hline \multicolumn{1}{c}{ Action } \\
Flood compensation through: \\
1. A Insurance plan purchased from Iran insurance company $+\mathrm{G}_{1}$ amount in cash from the government \\
2. B Insurance plan purchased from Asia insurance company $+\mathrm{G}_{1}$ amount in cash from the government \\
3. C Insurance plan purchased from MA insurance company $+\mathrm{G}_{1}$ amount in cash from the government \\
4. Only by $\mathrm{G}_{1}$ amount in cash from the government (property owner's do not have insurance plan) \\
Flood compensation through: \\
1. A Insurance plan purchased from Iran insurance company $+\mathrm{G}_{2}$ amount in cash from the government \\
2. B Insurance plan from Asia insurance company $+\mathrm{G}_{2}$ amount in cash from the government \\
3. C Insurance plan from MA insurance company $+\mathrm{G}_{2}$ amount in cash from the government \\
4. Only by $\mathrm{G}_{2}$ amount in cash from the government (property owner's do not have insurance plan) \\
Flood compensation through: \\
1. A Insurance plan purchased from Iran insurance company $+\mathrm{G}_{3}$ amount in cash from the government \\
2. B Insurance plan purchased from Asia insurance company $+\mathrm{G}_{3}$ amount in cash from the government \\
3. C Insurance plan purchased from MA insurance company $+\mathrm{G}_{3}$ amount in cash from the government \\
4. Only by $\mathrm{G}_{3}$ amount in cash from the government (property owner's do not have insurance plan)
\end{tabular}

\section{Results and Discussion}

\subsection{Calculated Flood Loss Based on Mentioned Scenarios (System Identification)}

In the first step, the data in related to flood economic losses has been extracted in paper of Moosakhaani et al. [22]. In this paper the flood economic loss has been estimated by HEC-FDA model based on the Evaluated Annual Damage Method as described follows:

$$
\begin{aligned}
& \mathrm{D}_{3}=10,149,933 \text { USD } \\
& \mathrm{D}_{2}=10,797,801 \text { USD } \\
& \mathrm{D}_{1}=12,220,237 \text { USD } \\
& \mathrm{D}_{0}=122,202 \text { USD }
\end{aligned}
$$

\subsection{Calculating Payoff Functions of Players (Forming Equations)}

Sample of payoff functions of the government and insurance companies have been calculated based on Eqs. (2) and (3), illustrated in Table 4.

Moreover, the payoff functions of the property owner have been calculated based on Eq. (1) illustrated in Table 5.

\subsection{Developing Comprehensive Financial Model for Flood Risk Management (Conflict Resolution)}

According to the results of various scenarios applied in this paper:

1) If flood occurs in $D_{3}$ scenario, the all players' payoffs are maximized based on Nash equilibrium. In addition, for flood

\begin{tabular}{|c|c|c|c|}
\hline Scenario & $\begin{array}{c}\mathrm{W}_{\mathrm{P}}^{\mathrm{t}+1} \\
\text { (based on Insurance plan of } \mathrm{A} \text { ) }\end{array}$ & $\begin{array}{c}\mathrm{W}_{\mathrm{P}}^{\mathrm{t}+1} \\
\text { (based on Insurance plan of } \mathrm{B} \text { ) }\end{array}$ & $\begin{array}{c}\mathrm{W}_{\mathrm{P}}^{\mathrm{t}+1} \\
\text { (based on Insurance plan of } \mathrm{C} \text { ) }\end{array}$ \\
\hline & $12,775,999,962$ & $12,777,014,344$ & $12,777,225,822$ \\
\hline \multirow[t]{3}{*}{$\mathrm{D}_{3}$} & $12,776,712,145$ & $12,777,726,526$ & $12,777,938,004$ \\
\hline & $12,777,331,138$ & $12,778,345,519$ & $12,778,556,998$ \\
\hline & $12,775,395,405$ & $12,776,409,786$ & $12,776,621,265$ \\
\hline \multirow[t]{3}{*}{$\mathrm{D}_{2}$} & $12,776,107,587$ & $12,777,121,968$ & $12,777,333,447$ \\
\hline & $12,776,726,581$ & $12,777,740,962$ & $12,777,952,440$ \\
\hline & $12,773,988,152$ & $12,775,002,533$ & $12,775,214,012$ \\
\hline \multirow[t]{2}{*}{$\mathrm{D}_{1}$} & $12,774,700,334$ & $12,775,714,716$ & $12,775,926,194$ \\
\hline & $12,775,319,328$ & $12,776,333,709$ & $12,776,545,188$ \\
\hline
\end{tabular}

Table 4. Calculation of Payoff Function for the Government and the Insurance Companies

\begin{tabular}{lcccc} 
Scenario & $\mathrm{W}_{\mathrm{G}}^{\mathrm{t}+1}$ & $\begin{array}{c}\mathrm{W}_{\mathrm{i}}^{\mathrm{t}+1} \\
\text { (based on Insurance plan of A) }\end{array}$ & $\begin{array}{c}\mathrm{W}_{\mathrm{i}}^{\mathrm{t}+1} \\
\text { (based on } \text { Insurance plan of B) }\end{array}$ & $\begin{array}{c}\mathrm{W}_{\mathrm{i}}^{\mathrm{t}+1} \\
\text { (based on Insurance plan of C) }\end{array}$ \\
\hline $\mathrm{D}_{3}$ & $18,423,030,896$ & $2,641,100,052$ & $634,056,108$ & $134,773,263$ \\
$\mathrm{D}_{2}$ & $16,999,900,512$ & $2,641,115,913$ & $634,060,489$ & $134,779,902$ \\
$\mathrm{D}_{1}$ & $15,670,452,595$ & $2,641,123,844$ & $634,062,680$ & $134,783,221$ \\
\hline
\end{tabular}

Table 5. Calculation of Payoff Function for Property Owner 
Table 6. Preferences and Priorities of the Nash Equilibrium Points in Comprehensive Financial Model

\begin{tabular}{|c|c|c|c|c|c|c|c|c|c|}
\hline Scenario & Strategy & $\begin{array}{l}\text { Loss } \\
\text { (USD) }\end{array}$ & $\begin{array}{l}\text { Government } \\
\text { Financial } \\
\text { Assistances } \\
\text { (USD) }\end{array}$ & $\begin{array}{l}\text { Premiums } \\
\text { Paid } \\
\text { by insured } \\
\text { (USD) }\end{array}$ & $\begin{array}{l}\text { Compensation by } \\
\text { Insurance } \\
\text { Company } \\
\text { (USD) }\end{array}$ & $\begin{array}{c}\text { Deductible } \\
\text { (\%) }\end{array}$ & $\begin{array}{c}\text { Insurance } \\
\text { Rate (/1000) }\end{array}$ & $\begin{array}{c}\text { Insurance } \\
\text { Plan }\end{array}$ & Priority \\
\hline $\mathrm{D}_{3}$ & $\mathrm{~S}_{10}$ & $10,149,933$ & 73,138 & $2,802,817$ & 149,288 & 20 & 25 & $\mathrm{C}$ & 1 \\
\hline $\mathrm{D}_{2}$ & $\mathrm{~S}_{9}$ & $10,797,801$ & 116,449 & $2,802,817$ & 149,288 & 20 & 25 & $\mathrm{C}$ & 2 \\
\hline $\mathrm{D}_{1}$ & $\mathrm{~S}_{8}$ & $12,220,237$ & 131,632 & $2,802,817$ & 149,288 & 20 & 25 & $\mathrm{C}$ & 3 \\
\hline $\mathrm{D}_{3}$ & $\mathrm{~S}_{19}$ & $10,149,933$ & 0 & $1,618,935$ & 67,179 & 10 & 31 & $A^{\prime}$ & 4 \\
\hline $\mathrm{D}_{2}$ & $\mathrm{~S}_{18}$ & $10,797,801$ & 0 & $1,618,935$ & 67,179 & 10 & 31 & $\mathrm{~A}^{\prime}$ & 5 \\
\hline $\mathrm{D}_{1}$ & $\mathrm{~S}_{17}$ & $12,220,237$ & 0 & $1,618,935$ & 67,179 & 10 & 31 & $\mathrm{~A}^{\prime}$ & 6 \\
\hline
\end{tabular}

losses compensation in $\mathrm{D}_{3}$ scenario, the government also should assist to property owner with the amount of $\mathrm{G}_{3}$. In addition, the property owner, as other players, should purchase the insurance plan of $\mathrm{C}$ (presented by MA insurance company). It is necessary to mention that MA insurance company, which has presented the insurance plan of $\mathrm{C}$, does not have adequate financial ability to pay the whole loss calculated. Therefore, for maximizing players' payoffs based on Nash equilibrium concept, C insurance plan must be provided by Iran Insurance Company (this insurance company has sufficient financial ability to compensate losses).

2) In second priority, the maximum payoff will occur in Nash equilibrium method in $\mathrm{D}_{2}$ scenario, when Iran insurance company by insurance plan of $\mathrm{C}$ compensated the losses and the government assist to the people by $\mathrm{G}_{2}$ amount.

3) In third priority, in $D_{1}$ scenario, the maximum payoff will occur when property owner should purchase insurance plan of $\mathrm{C}$ and the government assist $\mathrm{G}_{1}$ amount to property owner.

4) As the fourth priority, when flood occurred in $D_{3}$ scenario, the government should purchase insurance plan of $\mathrm{A}^{\prime}$ from Iran insurance company.

5) The fifth priority refers to $D_{2}$ scenario which insurance plan of $\mathrm{A}^{\prime}$ is purchased by the government.

6) Furthermore and ultimately, the sixth priority is related to purchase insurance plan by the government from Iran insurance company -which Insurance plan of $A^{\prime}$ is the case of here- in $\mathrm{D}_{1}$ scenario.

As the results show, maximum payoff is related to strategy in purchasing flood insurance with full coverage and government assistances simultaneously. The important point is that, the strategy in which, none of the players purchase flood insurance, is not game equilibrium which show the importance of insurance purchasing in flood risk management plans. In addition, the results show, the second priority is related to the strategy in which flood insurance is purchased by the government and its coverage is limited to buildings structures. This is a re-emphasis on the importance of purchasing flood insurance with full coverage. Finally, payoffs ranking of each game equilibrium has been estimated in Table 6 .

\subsection{Discussion}

The results illustrate:

1) The maximum payoff based on Nash equilibrium concept is obtained when an insurance plan has been purchased with full coverage and also there is government financial assistances simultaneously. This is demonstration of the requirement of a comprehensive plan for flood risk management.

2) The other results showed, the next priority of the Nash equilibrium is achieved when the government itself purchases flood insurance for the people.

3) On the other hand, the scenario, in which that, the loss compensation is carried out only by government assistance and the government or the people dose not purchase any insurance policy, the Nash equilibrium does not exist; which shows the importance of purchasing of flood insurance.

4) In comparing to other study, the authors tried to find game equilibrium for post disaster plan by evolutionary game theory, and developed a model further to take into account simultaneous actions by all players. By this way, families' choice percentage over insurance companies were calculated based on family income level those defined in three level including high, medium and poor levels [27]. In addition in other study conducted to show a framework for allocating compensation amounts between participants based on cooperative game theory, taking into account a principle of stability [32].

5) As a comparison of the present study with other studies, the present study has been able to develop a model (quantitatively and qualitatively simultaneously) for sharing financial responsibilities of players in flood risk management. In addition this model can be used as a practical guide in compensating for flood damage by the insurance companies and the governments, by considering the strategies of each player in the defined scenarios, the Nash equilibrium point has been calculated by maximizing payoff of all the players.

6) In addition, Nash equilibrium has the most dependency to deductible and insurance rates so that by decreasing insurance rate and increasing deductible, the highest priority is created for the Nash equilibrium.

\section{Conclusions}

Flood insurance as one of the most practical approaches in flood risk management plans, was investigated in this paper. The Results showed, obligation of government assistance, how to loss compensation and calculation of insurance premium by insurance companies 
were led to create conflict between the governments, insurance companies and people as players in flood risk management plans. Therefore in this paper, the game theory method was used for conflict resolution and developing a comprehensive financial model for sharing financial responsibility of each players. Following, collecting data and them investigation, the players were identified, theirs payoff functions were calculated and then action profiles and strategy profiles of each players were evaluated. Based on conflict's essence in this paper, which is non-cooperative, the Nash equilibrium method was used for conflict resolution and finding the best response and game equilibriums, which on that, all player's payoffs were maximized. Finally, comprehensive financial model was developed for sharing financial responsibility of all players and following results were achieved:

1) According to defined scenarios, there was game equilibrium in flood occurrence with 10,149,933 USD loss, which on that, all players' payoffs were maximized. Therefore, the players have ability to cover the flood costs up to the above amount. If more than the above amount of damage occurs, another mechanism must be provided to provide the above damages.

2) Investigating calculated payoffs of each player has been indicated the strategy of flood insurance purchasing (insurance with full coverage) with government financial assistances simultaneously has maximum payoff as the first priority. In this strategy, if insurance plan of $\mathrm{C}$ presents by Iran insurance company as the mono-public insurance company in Iran country with attendance of governance assistance, all players' payoffs will be maximized. This issue illustrates to failure of common insurance plan and requirement of existence exclusive flood insurance, more than ever in Iran.

3) Second priority related to strategy which on that flood insurance purchased by the government. The payoff reviewing of this strategy as the second priority (the building structures were covered merely in flood insurance), illustrates the significance of purchasing the flood insurance as full coverage, as well.

4) One of the most challenges in this research was the lack of flood insurance plans in study area. For resolving it, 6 flood insurance plan were developed by contribution of insurance companies in (A, B, C) plans and (A', B', C') plans.

5) From another point of view, it is feasible that an implementation of flood insurance will be occurred in Iran by the private sector, but in according to an uncertainty arising from natural disasters particularly in flood occurrence and unpredictable severe financial losses resulted from that, the performance of this type of insurance will be inconceivable without the government financial assistances.

This indicates the role of private insurance on the future impacts of flooding in the study area [33].

6) Other results of this paper are that the conflict resolution model in this case study in compensation methods of flood loss is most dependent on flood insurance in compared to governmental assistances. Therefore, it is recommended that existing insurance plans be revised based on the proposed insurance plan in this paper.

7) The remarkable note relates to the strategy wherein there is no Nash equilibrium in where neither people nor the government tends to purchase flood insurance. In this case, the participation of the third party, such as the governorship and the justice can change the future of the conflict, and result in moving to the Nash equilibrium. It is demonstrate that Justice is the most influential third party that can move the conflict towards a desired equilibrium [34].

8) The research findings help a lot in making people aware of the risk focus points and motivating them to buy flood insurance. As shown also in other research, by using an agent-based model that was focused on flood risk of surface water, it was analyzed how other partners could strengthen the insurance partnership by reducing flood risk and thus helping to maintain affordable insurance premiums [35].

Investigating related research to insurance plans as a way to flood loss compensation implies that financial incentives or regulations are needed to encourage people in purchasing flood insurance. In addition, according to purposes in this research, the relevant officials and the people in this region should be more aware of the strong dependence of the plans in flood risk management on the purchase of flood insurance policies by the people and by the government. To do this, informing and codified awareness, which is well scheduled, is essential and it is the requirement of mega policies.

In addition, investigating other researches show, there is significant difference between this paper and other similar papers:

1) In this paper, a comprehensive model was developed in which the financial responsibilities of each players were presented based on quantitative-qualitative combination strategies. Whereas in other studies, only one aspect has been considered and the models have been presented either quantitatively or qualitatively.

2) In addition, for first time in this paper the payoff functions of the government and insurance companies has been related to each other through the parameter of obligatory reinsurance premium, obligatory reinsurance compensation and performance tax paid to the government for conflict resolution by Nash equilibrium.

3) The developed financial model is most dependent on flood loss compensation by insurance companies and this shows the importance of flood insurance in losses compensation.

4) In addition, for increasing of calculations accuracy in flood insurance premium in this paper, franchise and deductible used simultaneously. Due to the catastrophic nature of damages caused by natural disasters such as floods and the importance of accurate calculations in their insurance, the existence of two parameters, franchise and deductible, helped to make accurate calculations in premiums and payment of damages.

5) The results showed, the high capability of the comprehensive financial model developed in this study in sharing the financial responsibilities of each players. In addition, for future studies it is suggested in flood loss calculation in addition of calculating flood financial loss, flood casualty loss will calculate as input of analyzing in game theory method.

6) On the other hand, based on the results and the strategies 
prioritization in game equilibrium according to Nash theory in this paper, developed model has most sensevity to Insurance rate and Deductible in insurance plan parameters. Therefore, the prioritization of strategies has direct relationship with deductible decreasing and insurance rate increasing. Therefore for future studies it is recommended, in order to achieve the maximum priority of game equilibrium in study area with mentioned insurance plans (C and $\mathrm{A}^{\prime}$ insurance plan), the insurance rate should be reduce and the deductible should be increased.

\section{Acknowledgment}

Islamic Azad University North Tehran Branch supported this research. Also thanks to Faculty of Marine Science and Technology at Islamic Azad University North Tehran Branch to technical support of this work and supportive participations.

\section{Authors Contributions}

M.M. (Ph.D. Candidate) designed the model and the computational framework, analyzed the data, and wrote the manuscript with template. L.S. (Assistant Professor) supervised the study. M.H.N. (Associate Professor) conceived of the resented original idea, devised the study, the main conceptual ideas and proof outline. M.T.S. (Assistant Professor) performed the analytic calculations. M.R. (Assistant Professor) designed and performed the experiments and literature review. All authors provided critical feedback and helped shape the research analysis and manuscript. All authors discussed the results and contributed the final manuscript.

\section{Reference}

1. Anand V, Oinam B. Future climate change impact on hydrological regime of river basin using SWAT. Glob. J. Environ. Sci. Manag. 2019;5:471-484.

2. Kousky C, Michel-Kerjan E. Examining flood insurance claims in the United States: six key findings. J. Risk Insur. 2017;84:819-850.

3. Centre for Research on the Epidemiology of Disasters (CRED). Flash floods sharing of field experience- kerala. Cred Crunch 53. December 2018. DOI:10.13140/RG.2.2.31415.78241

4. Ibeje AO, Ekwueme BN. Regional Flood Frequency Analysis using Dimensionless Index Flood Method. Civ. Eng. J. 2020;6:2425-2436.

5. Habeeb NJ, Weli ST. Combination of GIS with Different Technologies for Water Quality: An Overview. HighTech. Innov. J. 2021;2:262-272.

6. Kavianpour M, Seyedabadi M, Moazami S, Moazami OA. Copula Based Spatial Analysis of Drought Return Period in Southwest of Iran. J. Period. Polytech. Chem. Eng. 2020;64:1051-1063.

7. Latif S, Mustafa F. Bivariate Hydrologic Risk Assessment of Flood Episodes using the Notation of Failure Probability. Civ. Eng. J. 2020;6:2002-2023.
8. Organisation for Economic Co-operation and Development. Financ. Mmanage. Flood Risk. 2016;1-136.

9. Breuer N. Multiple Losses, ex ante Moral Hazard, and the Implications for Umbrella Policies. J. Risk Insur. 2005;72: 525-538.

10. Doherty N, Smetters K. Moral Hazard in Reinsurance Markets. J. Risk Insur. 2005;72:375-391.

11. Wouter Botzen WJ, Kunreuther H, Michel-Kerjan E. Protecting against disaster risks: Why insurance and prevention may be complements. J. Risk Uncertain. 2019;59:151-169.

12. Gradeci K, Labonnote N, Sivertsen E, Time Be. The use of insurance data in the analysis of Surface Water Flood events - A systematic review. J. Hydrol. 2019;568:194-206.

13. Surminski S, Thieken A. Promoting flood risk reduction: the role of insurance in Germany and England. Earths Future. 2017;5:979-1001.

14. Zhongchen Hu. Salience and Households' Flood Insurance Decisions. Social Science Research Network (SSRN). Available at SSRN: https://ssrn.com/abstract=3759016 or http://dx.doi. org/10.2139/ssrn.3759016

15. Hudson P. A comparison of definitions of affordability for flood risk adaption measures: a case study of current and future risk-based flood insurance premiums in Europe. Mitig. Adapt. Strategies Glob. CHG. 2018;23:1019-1038.

16. Knighton J, Buchanan B, Guzman C, Elliott R, White E, Rahm B. Predicting flood insurance claims with hydrologic and socioeconomic demographics via machine learning: Exploring the roles of topography, minority populations, and political dissimilarity. J. Environ. Manage. 2020;272:1-13.

17. Yu J, Kilgour DM, Hipel KW, Zhao M. Power asymmetry in conflict resolution with application to a water pollution dispute in China. Water Resour. Res. 2015;51:8627-8645.

18. Boonen Tim J, Pantelous Athanasios A, Wu Renchao. Non-cooperative dynamic games for general insurance markets. Insur. Math. Econ. 2018;78:123-135.

19. Dosis A. Nash equilibrium in competitive insurance. Econ. Lett. 2017;152:5-8.

20. Nagurney A, Flores EA, Soylu CA. Generalized Nash Equilibrium network model for post-disaster humanitarian relief. Transp. Res. Part E Policy Pract. 2016;95:1-18.

21. Hudson P, Wouter Botzen WJ, Aertsb Jeroen CJH. Flood insurance arrangements in the European Union for future flood risk under climate and socioeconomic change. Glob. Environ. CHG. 2019;58:1-13.

22. Moosakhaani M, Salimi L, Sadatipour MT, Rabbani M. Developing Flood Economic Loss Evaluation Model in Residential and Commercial Sectors (Case Study: Darband and Golab Darreh Rivers). Environ. Energy Econ. Res. 2020;4: 215-229.

23. Hamidi M, Liao L, Szidarovszky F. Non-cooperative and cooperative game-theoretic models for usage-based lease contracts. Eur. J. Oper. Res. 2016;255.163-174.

24. Dalit DA. Market share analysis and non - cooperative game theory with applications in Swiss Health insurance [Dissertation]. Lausanne: Univ. of Lausanne; 2019.

25. Abdel Hamid H.T, Wenlong W, Qiaomin L. Environmental sensitivity of flash flood hazard using geospatial techniques. Glob. 
J. Environ. Sci. Manag. 2020;6:31-46.

26. Osborne MJ. An introduction to Game Theory. Oxford: University Press; 2000.

27. Eid MS, El-adaway IH, Coatney KT. Evolutionary Stable Strategy for Post-Disaster Insurance: A Game Theory Approach. J. Manage. Eng. 2015;31:1-9.

28. Dastbaz H. Applicable reinsurance. 3rd ed. Insurance Research Center of Iran press; 2014. p. 8-10.

29. Paudel Y, Botzen WJW, Aerts JCJH, Dijkstra TK. Risk allocation in a public-private catastrophe insurance system: an actuarial analysis of deductibles, stop-loss, and premiums. J. Flood Risk Manage. 2015;8:116-134.

30. Roder G, Paul H, Paolo T. Flood Risk Perceptions and the Willingness to pay for flood insurance in the Veneto region of Italy. Int. J. Disaster Risk Reduct. 2019;37:1-34.

31. Insurance Information Institute. Understanding Your Insurance
Deductibles. Accessed March 27;2020:1-4.

32. Álvarez X, Gómez-Rúab M, Vidal-Puga J. River flooding risk prevention: A cooperative game theory approach. J. Environ. Manage. 2019;248:1-8.

33. Yiannakoulias N, Darlington JC, Elshorbagy A, Rajab B. Meta-analysis based predictions of flood insurance and flood vulnerability patterns in Calgary, Alberta. Appl. Geog. 2018;96:41-50.

34. Zanjanian H, Abdolabadi $H$, Niksokhan $M H$, Sarang A. Influential third party on water right conflict: A Game Theory approach to achieve the desired equilibrium (case study: Ilam dam, Iran). J. Environ. Manage. 2018;214:283-294.

35. Crick F, Jenkins K, Surminski S. Strengthening insurance partnerships in the face of climate change - Insights from an agent-based model of flood insurance in the UK. Sci. Total Environ. 2018;636:192-204. 